\title{
Plugging in or going wireless: strategies for interspecies electron transfer
}

\author{
Pravin Malla Shrestha ${ }^{1,2}$ * and Amelia-Elena Rotaru ${ }^{3}$ \\ 1 Department of Microbiology, University of Massachusetts, Amherst, MA, USA \\ ${ }^{2}$ Energy Biosciences Institute, University of California, Berkeley, CA, USA \\ ${ }^{3}$ Nordic Center for Earth Evolution, University of Southern Denmark, Odense, Denmark
}

\section{Edited by:}

Luis Raul Comolli, Lawrence Berkeley National Laboratory, USA

\section{Reviewed by:}

Wei Shi, North Carolina State

University, USA

Rizlan Bernier-Latmani, École

Polytechnique Fédérale de Lausanne, Switzerland

\section{${ }^{*}$ Correspondence:}

Pravin Malla Shrestha, Energy Biosciences Institute, University of California, Berkeley, CA 94704, USA e-mail:pravin@berkeley.edu
Interspecies exchange of electrons enables a diversity of microbial communities to gain energy from reactions that no one microbe can catalyze. The first recognized strategies for interspecies electron transfer were those that relied on chemical intermediates that are recycled through oxidized and reduced forms. Well-studied examples are interspecies $\mathrm{H}_{2}$ transfer and the cycling of sulfur intermediates in anaerobic photosynthetic communities. Direct interspecies electron transfer (DIET) in which two species establish electrical contact is an alternative. Electrical contacts documented to date include electrically conductive pili, as well as conductive iron minerals and conductive carbon moieties such as activated carbon and biochar. Interspecies electron transfer is central to the functioning of methaneproducing microbial communities. The importance of interspecies $\mathrm{H}_{2}$ transfer in many methanogenic communities is clear, but under some circumstances DIET predominates. It is expected that further mechanistic studies and broadening investigations to a wider range of environments will help elucidate the factors that favor specific forms of interspecies electron exchange under different environmental conditions.

Keywords: syntrophy, diet, interspecies electron transfer, conductive pili, coculture

\section{INTRODUCTION}

Interspecies electron transfer plays a key role in the functioning of methane-producing microbial communities, which have a significant impact on the global carbon cycle (Stams and Plugge, 2009; Sieber et al., 2012). Organic matter mineralization to methane by microbial processes contributes to $69 \%$ of the atmospheric $\mathrm{CH}_{4}$ (Conrad, 2009) and it involves four major steps (Figure 1A):

(1) Hydrolytic bacteria break down complex compounds such as polysaccharides, proteins, nucleic acids, and lipids to monomeric substances (Schink and Stams, 2013), (2) Primary fermenters convert monomeric substances to $\mathrm{H}_{2}$ /formate, $\mathrm{CO}_{2}$ and small organic molecules such as lactate, succinate, fatty acids, and acetate (Morris et al., 2013; Schink and Stams, 2013), (3) Syntrophic bacteria carryout secondary fermentation of small organic molecules to produce acetate, formate, $\mathrm{H}_{2}$ and $\mathrm{CO}_{2}$ (Morris et al., 2013; Schink and Stams, 2013), or releases electrons for direct electric connections (Summers et al., 2010; Rotaru et al., 2014), (4) Methanogenic Archaea uses electrons from $\mathrm{H}_{2}$ /formate/shuttles or directly to reduce $\mathrm{CO}_{2}$ to $\mathrm{CH}_{4}$ (Morris et al., 2013; Rotaru et al., 2014; Sieber et al., 2014).

Interspecies electron transfer via $\mathrm{H}_{2}$ /formate has been extensively reviewed in recent years (Morris et al., 2013; Schink and Stams, 2013; Sieber et al., 2014). Besides, $\mathrm{H}_{2}$ /formate, there are many important mechanisms of interspecies electron transfer reported, which include but are not limited to pili mediated direct interspecies electron transfer (DIET; Summers et al., 2010; Morita et al., 2011; Nagarajan et al., 2013; Shrestha et al., 2013a,b; Rotaru etal., 2014) and mineral mediated direct intrespecies electron transfer (Kato et al., 2012a,b; Liu et al., 2012, 2014; Chen et al., 2014), or by shuttle molecules like cysteine (Kaden et al., 2002), sulfur compounds (Biebl and Pfennig, 1978; Milucka et al., 2012), and humics (Lovley et al., 1999; Liu etal., 2012). This review discusses recent findings on interspecies electron transfer during syntrophic interactions, with the main focus on DIET mechanisms.

\section{$\mathrm{H}_{2}$ AND FORMATE AS ELECTRON TRANSFER MOLECULES}

$\mathrm{H}_{2}$ and formate are important electron transfer molecules that are reported in various methanogenic environments (Schink and Stams, 2006, 2013; Stams and Plugge, 2009), these are described briefly under separate headings below:

\section{$\mathrm{H}_{2}$ AS ELECTRON TRANSFER MOLECULE}

Interspecies electron transfer via $\mathrm{H}_{2}$ was first demonstrated almost four decades ago in a defined co-culture (Bryant et al., 1967) of the "S organism," which converted ethanol to acetate and $\mathrm{H}_{2}$, only in the presence of Methanobacterium ruminantium, which consumed $\mathrm{H}_{2}$ for the reduction of $\mathrm{CO}_{2}$ to $\mathrm{CH}_{4}$ (Bryant etal., 1967). $\mathrm{H}_{2}$ is a very powerful electron donor under anoxic conditions and must be continuously removed by partner organism in order for the syntrophic interaction to take place (Nedwell and Banat, 1981; Lovley and Ferry, 1985; Kleerebezem etal., 1999; Wintermute and Silver, 2010). The generation of $\mathrm{H}_{2}$ is energetically unfavorable at $\mathrm{H}_{2}$ partial pressures above $10^{-3}$ bar (Schink and Stams, 2013), however, syntrophic microorganisms bypass this energetic barrier by coupling the unfavorable $\mathrm{H}_{2}$ production with 


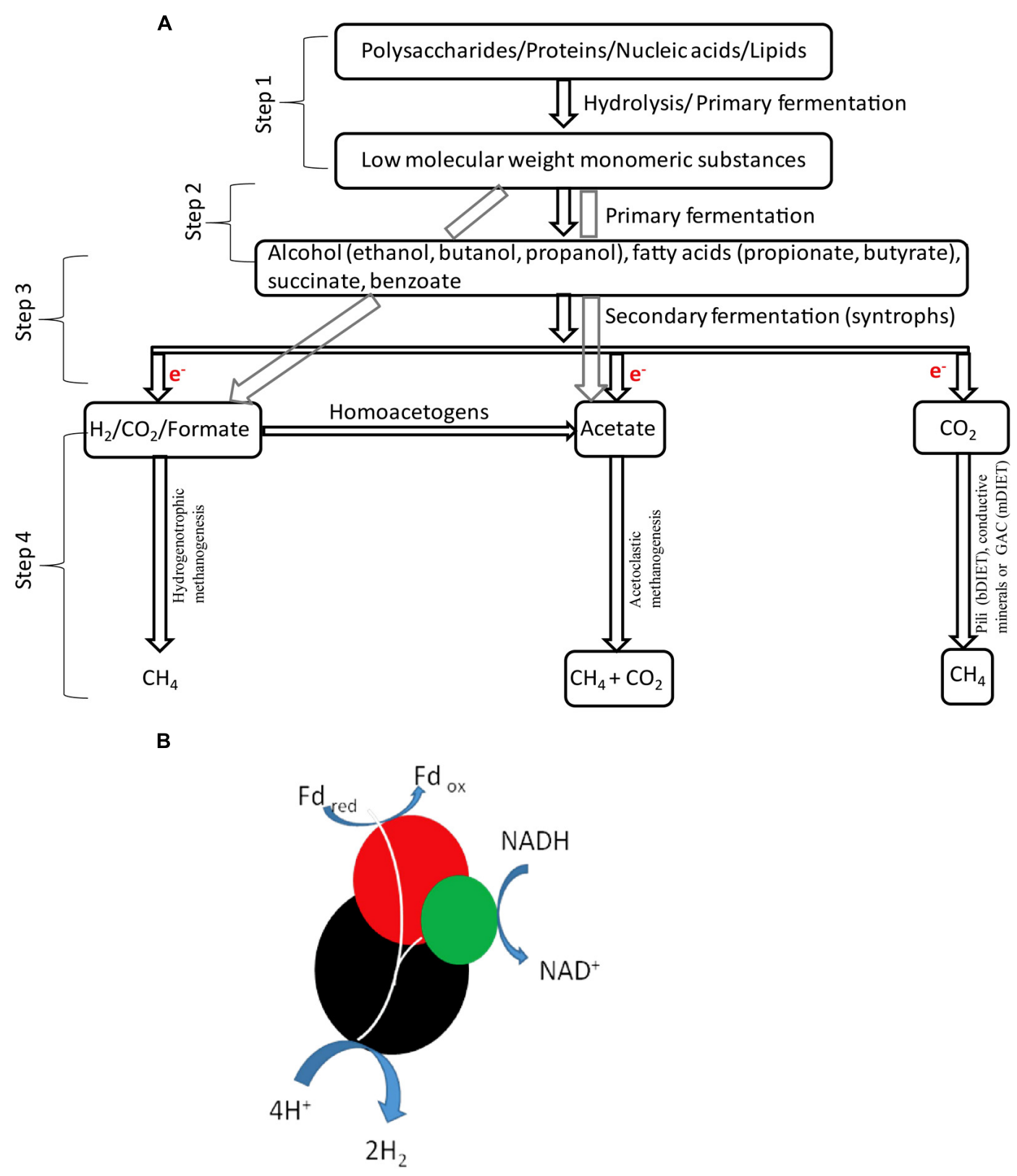

FIGURE 1 | Organic matter degradation in methanogenic environments (A). Sketch of the coupling of $\mathrm{H}_{2}$ with the energetically favorable oxidation of a reduced ferredoxin in the presence of putative NADH-linked confurcating hydrogenases [modified from Mclnerney et al., 2011; (B)].

the energetically favorable oxidation of a reduced compound like ferrodoxin (Figure 1B), a process known as electron confurcation (Schut and Adams, 2009; Sieber etal., 2010, 2012). Confurcating hydrogenases are found in the genomes of all $\mathrm{H}_{2}$ generating syntrophs described to date (Sieber et al., 2010, 2012).

\section{FORMATE AS ELECTRON TRANSFER MOLECULE}

Formate is an alternative to $\mathrm{H}_{2}$ and could also act as an electron carrier between syntrophic partners (Thiele and Zeikus, 1988; Boone et al., 1989; Hattori et al., 2001; de Bok et al., 2004;
Stams et al., 2006; Stams and Plugge, 2009). The use of formate as an electron transfer molecule has been noticed especially in co-cultures thriving on proteins (Zindel et al., 1988) or fatty acids like propionate and butyrate (de Bok etal., 2004; Sousa etal., 2007). Certain communities might favor formate transfer because formate has ca. three times higher diffusion coefficient as compared to $\mathrm{H}_{2}$, and allows larger mass transfer to methanogens (Boone etal., 1989). It has been also reported that some syntrophic interactions uses both formate and $\mathrm{H}_{2}$ to transfer electrons between species (Boone et al., 1989; Dong and Stams, 1995; Stams et al., 2006; Rotaru et al., 2012). This dual mechanism of electron 
A

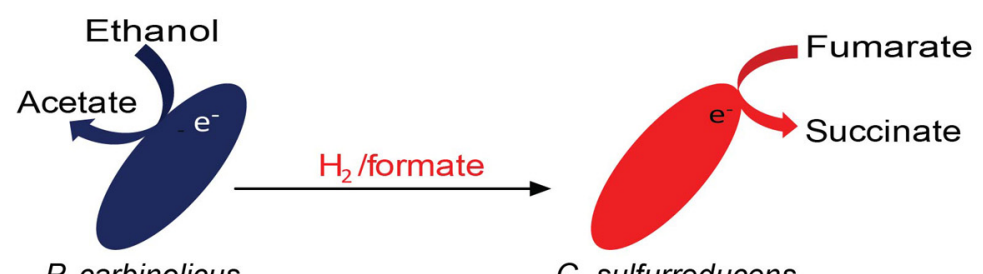

$\mathrm{H}_{2} /$ Formate

mediated electron transfer

(Rotaru et al., 2012)

B

P. carbinolicus

G. sulfurreducens

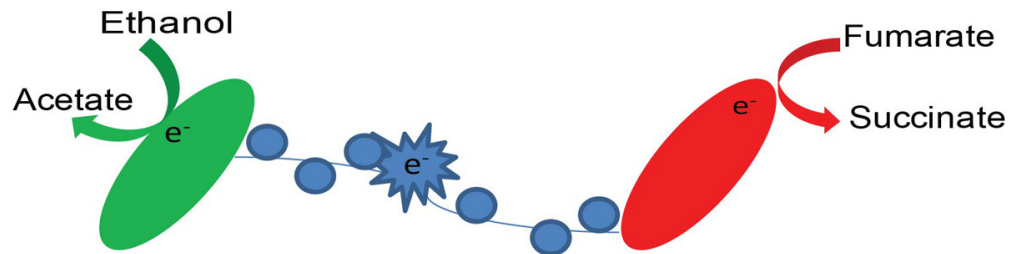

G. metallireducens

G. sulfurreducens

C

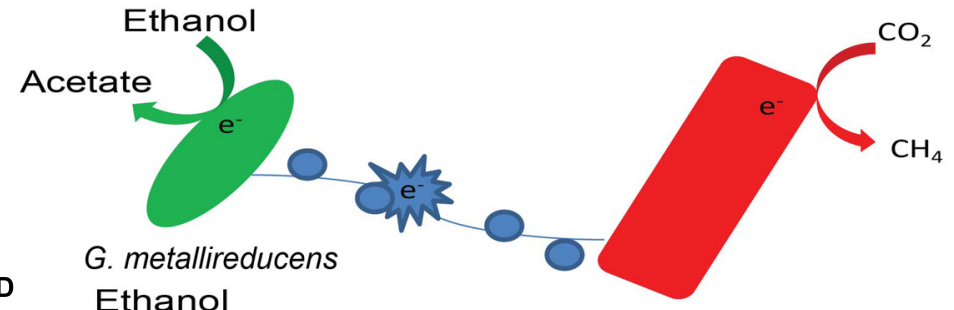

bDIET mediated

electron transfer

(Rotaru et al., 2014)

D

Ethanol

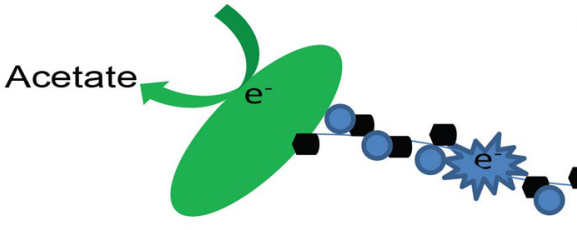

M. harudinacea

bDIET mediated

electron transfer

(Summers et al., 2010)

G. metallireducens

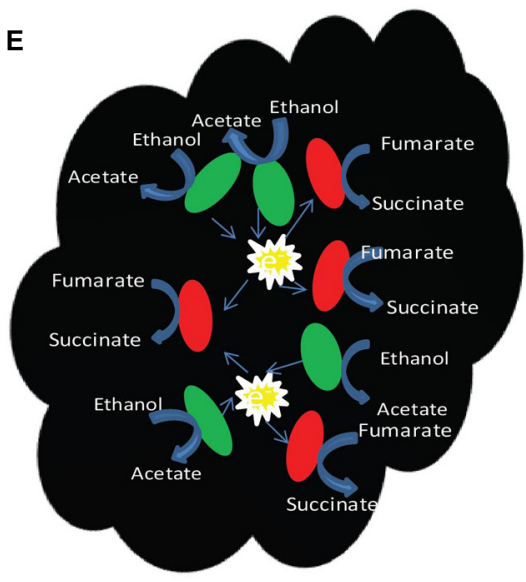

G. sulfurreducens

mDIET mediated

electron transfer via

Granulated activated carbon (GAC)

between

G. metallireducens and

G. sulfurreducens

(Liu et al., 2012)

mDIET mediated electron transfer via magnetite nano particles (Liu et al., 2014)

Succinate

FIGURE 2 | Examples of mechanisms of electron transfer. $\mathrm{H}_{2}$ transfer between $P$. carbinolicus and $G$. sulfurreducens (A), bDIET between $G$. metallireducens and $G$. sulfurreducens (B), mineral mediated mDIET between $G$. metallireducens and $G$. sulfurreducens with nano-sized minerals (D) or GAC (E) in the presence of ethanol as the electron donor and fumarate as the electron acceptor. DIET in a co-culture of G. metallireducens and Methanosaeta harudinacea where ethanol was used as electron donor and $\mathrm{CO}_{2}$ is reduced to $\mathrm{CH}_{4}$ by Methanosaeta using electrons received directly from $G$. metallireducens via bDIET (C). 
transfer using $\mathrm{H}_{2}$ and formate (Figure 2A) has been studied in detail using deletion mutants, in a co-culture of Pelobacter carbinolicus and Geobacter sulfurreducens (Rotaru et al., 2012). For example, when a co-culture was established with a hydrogenase mutant (hybL) of G. sulfurreducens, the formate dehydrogenase $(f d n G)$ gene of G. sulfurreducens was over-expressed (Rotaru et al., 2012).

\section{ELECTRON TRANSFER VIA SHUTTLE MOLECULES}

Electron shuttles are chemical compounds that facilitates the transfer of electrons to and from bacteria these may include sulfur compounds (Biebl and Pfennig, 1978), humic substances (Lovley et al., 1996, 1998, 1999; Newman and Kolter, 2000), and flavins (Marsili et al., 2008; von Canstein et al., 2008; Brutinel and Gralnick, 2012), etc.

\section{SULFUR COMPOUNDS AS MEDIATORS FOR INTERSPECIES ELECTRON TRANSFER}

Sulfur compounds as shuttle were first discovered between green sulfur bacteria and sulfate-reducing bacteria (SRB; Biebl and Pfennig, 1978). $S(0)$ is converted to sulfide by a sulfate reducing bacteria and then recycled back to $S(0)$ by a photosynthetic greensulfur bacteria creating an interspecies S-cycle (Biebl and Pfennig, 1978). The second discovered S-based interspecies interaction used cysteine as electron shuttle between G. sulfurreducens and Wolinella succinogenes, growing with acetate as electron donor and nitrate as electron acceptor (Kaden et al., 2002). S-compounds were also found responsible for electron transfer between anaerobic methane oxidizing Archaea (ANME) and sulfate reducing bacteria (Boetius et al., 2000), which oxidizes methane with sulfate, one of the most studied, yet least understood interactions. The members of the anaerobic oxidation of methane consortia were initially thought to exchange electrons via methyl-sulfides (Moran et al., 2008), however, more recently the electron carrier within the consortium was revealed to be polysulfides (Milucka et al., 2012).

\section{HUMICS AND HUMICS EQUIVALENTS AS ELECTRON SHUTTLES}

Humic substances are ubiquitous in nature (Lovley et al., 1996; Bittner et al., 2007). The humic substance analog, anthraquinone disulphonate (AQDS) serves as an electron shuttles between $G$. metallireducens and G. sulfurreducens (Liu et al., 2012), or between G. metallireducens and W. succinogenes (Lovley et al., 1999). This came as no surprise because it is known that certain microorganisms can use $\mathrm{AH}_{2}$ QDS as electron donor (Lovley et al., 1999), while others use AQDS as electron acceptor (Lovley et al., 1996). However, AQDS cannot mediate electron transfer in G. metallireducens and $M$. barkeri co-cultures, likely because of the redox potential of the AQDS couple is too high to reduce carbon $\left(\mathrm{E} 0{ }^{\prime}=-184 \mathrm{mV}\right)$ to reduce carbon dioxide to methane $\left(\mathrm{E} 0^{\prime}=-240 \mathrm{mV}\right.$; Liu et al., 2012).

\section{FLAVINS AS ELECTRON SHUTTLES}

Flavins were also noted to improve electron transfer to electrodes in Shewanella biofilms (Marsili et al., 2008; von Canstein et al., 2008; Brutinel and Gralnick, 2012) yet their impact on interspecies interactions remains to be reported.

\section{DIRECT INTERSPECIES ELECTRON TRANSFER}

To clearly distinguish between conductive mineral mediated DIET and direct cell contact DIET, we have subcategorized the pili mediated electron transfer, as biological DIET (bDIET), and the conductive mineral mediated DIET, as mineral DIET (mDIET).

\section{BIOLOGICAL DIET}

Biological DIET (Figures 2B,C) was first described in G. metallireducens and G. sulfurreducens co-cultures, growing in a defined minimal medium with ethanol as electron donor and fumarate as electron acceptor (Summers et al., 2010). Tightly associated aggregates were consistently noticed in co-cultures growing via bDIET (Summers et al., 2010; Shrestha et al., 2013a; Rotaru et al., 2014) but not during growth via $\mathrm{H}_{2}$ /formate electron transfer (Rotaru etal., 2012). The mechanism for bDIET in Geobacter co-cultures was intensely studied during the past few years, combining phenotypic, genetic, transcriptomics, proteomics analysis (Summers et al., 2010; Shrestha et al., 2013a,b). bDIET might be favored over $\mathrm{H}_{2}$ or formate transfer under certain conditions (Lovley, 2011) as demonstrated using genome-scale models including genomic, transcriptomic and physiological data (Nagarajan et al., 2013). The absence of $\mathrm{H}_{2}$ /formate mediated electron transfer in the co-culture was best shown by the ability of G. metallireducens to generate successful syntrophic co-cultures with a double mutant of $G$. sulfurreducens $(\Delta h y b L \Delta f d n G)$ incapable of $\mathrm{H}_{2}$ or formate uptake (Rotaru et al., 2012). Furthermore, bDIET is seemingly capable to produce successful co-cultures in the absence of acetate transfer as supportive mechanism of electron exchange as revealed in a recent study (Shrestha et al., 2013a) in co-cultures of G. metallireducens with strain of G. sulfurreducens depleted in acetate utilization capacity, a citrate synthase mutant ( $\Delta g l t A$; Ueki and Lovley, 2010). This study clearly revealed that bDIET alone is sufficient for energy conservation in syntrophic co-cultures.

Biological DIET interactions with fumarate as terminal electron acceptors are probably not ecologically relevant, but more recently bDIET was discovered in co-cultures of G. metallireducens with Methanosaeta harudinacea (Rotaru et al., 2014). These two genera of methanogens are responsible for the majority of methane emission in environments such as paddy soils (Grosskopf et al., 1998; Feng et al., 2013) or anaerobic digesters (Vavilin et al., 2008; Morita et al., 2011; Rotaru et al., 2014; Ying et al., 2014). Only these acetoclastic methanogens were capable of bDIET-interactions with G. metallireducens, whereas hydrogenotrophic methanogens were not (Rotaru et al., 2014). Methanosaeta was shown to use electrons directly for the reduction of $\mathrm{CO}_{2}$ to methane because the methanogen converted $1 / 3$ of the ${ }^{14} \mathrm{C}$-bicarbonate to ${ }^{14} \mathrm{C}$ methane (Rotaru etal., 2014). Other shuttles were excluded as electron transferring mechanisms because a pili-deficient $G$. metallireducens could not produce successful co-cultures with Methanosaeta or Methanosarcina (Rotaru et al., 2014).

\section{Role of pili in bDIET}

Pili are known to have an important role in biofilm formation (Moreira etal., 2006; Reguera et al., 2007; Oxaran et al., 2012; Snider etal., 2012), but also for the conductive properties of Geobacter biofilms (Summers et al., 2010; Malvankar 
et al., 2011; Malvankar and Lovley, 2012, 2014; Vargas et al., 2013). Co-cultures do not grow when initiated with a strain of either G. metallireducens (Summers et al., 2010) or G. sulfurreducens (Rotaru etal., 2014) in which the gene for PilA is deleted, confirming the importance of conductive pili (Reguera et al., 2005, 2006; Lovley, 2011; Malvankar et al., 2011) networks for bDIET. It has been proposed that the stacking of $\pi-\pi$ orbitals of five aromatic amino-acids in the carboxyl-terminus of PilA, the pilin monomer, contribute to the metallic-like conductivity similar to that of conductive organic polymers (Vargas et al., 2013). A G. sulfurreducens strain deficient in the five aromatic amino acids (ARO5), the pili were still produced with properly localized OmcS and yet the biofilms of ARO5 showed greatly diminished conductivity (Vargas et al., 2013). In another study, the gene for conductive pili in G. sulfurreducens was replaced with the non-conductive pilA gene of Pseudomonas aeruginosa PAO1 (Liu et al., 2013) generating a mutant strain PAO1, which can express properly assembled $P$. aeruginosa pili ornamented by outer surface c-type cytochromes. However, PAO1 biofilms had significantly lower conductivity than wild type $G$. sulfurreducens and was unable to reduce $\mathrm{Fe}^{3+}$-oxides or produce current (Liu etal., 2013). The lack of conductivity in PAO1 biofilms indicates that three out of five aromatic amino acids at the C-terminus domain are necessary for conductivity (Liu et al., 2013). These findings validated that OmcS alone on scaffold-pili is insufficient to confer conductivity to Geobacter biofilms, in contrast to a recent hypothesis, which suggested that conductivity is the result of electron-hopping via cytochromes aligned on the pili of G. sulfurreducens (Strycharz-Glaven et al., 2011).

\section{Role of cytochromes in bDIET}

Geobacter sulfurreducens was used as model organism for the study of extracellular electron transfer, and several studies revealed that besides pili, G. sulfurreducens require a multitude of extracellular and periplasmic cytochromes for insoluble $\mathrm{Fe}^{3+}$ oxide reduction (Lloyd etal., 2003; Butler etal., 2004; Qian etal., 2007, 2011; Aklujkar et al., 2009; Lovley et al., 2011; Lovley, 2012), current production (Nevin et al., 2009; Inoue et al., 2010), or current uptake on electrodes (Holmes et al., 2006; Strycharz et al., 2011). However, there are slight differences in the types of cytochromes expressed during growth in electron-donating and electron up-taking modes (Strycharz et al., 2011).

Geobacter sulfurreducens growing via bDIET with G. metallireducens highly expresses an extracellular c-type cytochrome, OmcS (Summers et al., 2010; Shrestha et al., 2013a,b). OmcS decorates the pili of G. sulfurreducens (Leang et al., 2010; Summers et al., 2010) and is required for bDIET and $\mathrm{Fe}^{3+}$ reduction (Mehta et al., 2005; Ding et al., 2008; Qian et al., 2011) but not for current production (Nevin et al., 2009). OmcS is not necessary while growing via $\mathrm{H}_{2}$ interspecies transfer with $P$. carbinolicus (Rotaru et al., 2012).

Another extracellular cytochrome OmcZ, which helps G. sulfurreducens achieve high current densities in single species biofilms (Nevin et al., 2009; Richter et al., 2009), was not required for bDIET in G. sulfurreducens - G. metallireducens co-cultures (Shrestha et al., 2013b) or during iron oxide reduction (Nevin et al., 2009).
There is no correspondence between the well studied extracellular cytochromes in G. sulfurreducens and G. metallireducens, and today we have yet no clear understanding, about the exact role of each cytochrome in G. metallireducens during extracellular electron transfer processes. And yet it must be noted that extracellular cytochrome like OmcS in the electron acceptor strain, $G$. sulfurreducens were highly relevant for the interspecies association. How exactly they aid the electron transfer process is yet to be uncovered.

\section{bDIET in environmental communities}

The possible existence of bDIET in the natural ecosystem was first reported by Morita et al. (2011), while studying the mechanism of interspecies electron exchange in the natural methanogenic communities that formed conductive aggregates in a simulated anaerobic wastewater digester converting brewery wastes to methane. The microbial community structure in up-flow anaerobic sludge blanket digester aggregates showed the predominance of Geobacter spp. (Morita et al., 2011; Rotaru et al., 2014). It is interesting to note that in most of the methanogenic environments where bDIET is reported, Geobacter spp. are abundant (Kato et al., 2012a; Aulenta et al., 2013; Zhou et al., 2013a; Rotaru et al., 2014), which is probably because Geobacter spp. form conductive networks using pili (Malvankar et al., 2011; Malvankar and Lovley, 2012) and transfer electrons to methanogens such as Methanosaeta (Morita et al., 2011; Rotaru etal., 2014). Similar species abundance has also been reported in enrichment culture converting coal to methane, where Geobacter and Methanosaeta were the dominant genera (Jones et al., 2010) possibly using coal as an electron donor and an electron transfer mediator.

\section{MINERAL MEDIATED DIET (mDIET)}

The need to produce biological conductive molecular networks can be averted by the addition of conductive minerals (Liu et al., 2012, 2014). mDIET could take place via non-biological conductive networks of semi-conductive minerals (Figures 2D,E) like nano-magnetite (Kato et al., 2012a,b; Liu et al., 2014), granulated activated carbon (GAC; Liu et al., 2012) or biochar (Chen et al., 2014) in the absence of molecular conduits.

For example, electrically conductive magnetite nano-particles facilitate mDIET from G. sulfurreducens to Thiobacillus denitrificans, accomplishing acetate oxidation coupled to nitrate reduction (Kato etal., 2012b). Recently, magnetite nano-particles were shown to compensate for the absence of OmcS on the pili of a deficient G. sulfurreducens co-cultured with G. metallireducens in the presence of ethanol and fumarate (Liu et al., 2014; Figure 2D). Another conductive material, GAC promotes mDIET, bypassing biologically produced electrical conduits (Liu et al., 2012), as evident from the ability to restore syntrophic metabolism in co-cultures deficient in pili or cytochromes (Liu et al., 2012).

\section{mDIET in environmental communities}

Although extracellular appendages are required for the respiration of extracellular electron acceptors (Reguera et al., 2005; Tremblay et al., 2012), they can be replaced with conductive materials which can mediate electron transfer between cells during mDIET. Naturally occurring minerals could offer ecological advantages 
because of their abundance in natural ecosystems (Kato et al., 2012b), where they could aid mDIET in the absence of pre-evolved molecular conduits. Iron is one of the most ubiquitous metals in Earth's crust (Braunschweig et al., 2013) and could act as conductive mediator for mDIET, demanding less energetic investment from the species exchanging electrons because there would be no need to produce extracellular components for biological electrical connections (Kato et al., 2012b). For example, magnetite, a conductive iron (II\&III)-oxide, stimulated methane production in rice paddy soils and enriched for Geobacter and Methanosarcina species, which likely exchanged electrons via magnetite minerals (Kato et al., 2012a; Zhou et al., 2013b). Electrically conductive magnetite $\left(\mathrm{Fe}_{3} \mathrm{O}_{4}\right)$ nano-particles could also enhance reductive dechlorination of trichloroethane, an ubiquitous groundwater pollutant, by allowing electrons to be transferred extracellular from acetate oxidizing microorganisms to trichloroethane dechlorinating microorganisms (Aulenta et al., 2013). In this study the abundant microorganisms were also Geobacter spp., which accounted for $50 \%$ of the total bacterial population (Aulenta et al., 2013).

Similarly, it has been reported that poorly crystalline akaganeite ( $\beta$-polymorph of $\mathrm{FeOOH}$ ) enhanced mDIET to methanogens in slurries from river sediments (Jiang et al., 2013). In such slurries, Clostridium coupled $\mathrm{Fe}^{3+}$-akaganeite reduction to $\mathrm{Fe}^{2+}$ with acetate oxidation. Partly, electrons from $\mathrm{Fe}^{2+}$ were used by the methanogen to convert bicarbonate to methane. Partly, $\mathrm{Fe}^{2+}$ ions were re-adsorbed onto akaganeite nano-rods, followed by re-precipitation as structural $\mathrm{Fe}^{3+}$ with the simultaneous formation of goethite ( $\alpha$-polymorph of FeOOH) nanofibres (Jiang et al., 2013).

Anthraquinone disulphonate was also suggested to facilitate mDIET between Geobacter spp. and Methanosarcina spp. in rice paddies (Zhou et al., 2013b). The impact of AQDS on methanogenesis is in contrast with studies in defined co-cultures of Geobacter and Methanosarcina (Liu et al., 2012). However, soils are not well-defined systems, and it is possible that in soil other interactions happen between humics and soil components, which should be further investigated.

\section{IMPLICATIONS}

The electron exchange between syntrophic partners growing together by bDIET requires cells to develop efficient conductive biological contacts via pili and cytochromes in the absence of conductive mediators (mDIET). However, little is known about the importance of bDIET/mDIET-based interactions in the environment or in man-made systems. A better understanding could help devise better strategies for wastewater digestion, or to control methane emission in environments where such emission are high, like landfills, or rice paddies.

\section{ACKNOWLEDGMENTS}

We would like to thank Prof. Derek R. Lovley for reading manuscript and providing valuable suggestions. Pravin Malla Shrestha was supported by U.S. Department of Energy grant no. DESC0004485. Amelia-Elena Rotaru was supported by a FNU grant no. DFF-1325-00025 awarded by the Danish Research Council.

\section{REFERENCES}

Aklujkar, M., Krushkal, J., Dibartolo, G., Lapidus, A., Land, M. L., and Lovley, D. R. (2009). The genome sequence of Geobacter metallireducens: features of metabolism, physiology and regulation common and dissimilar to Geobacter sulfurreducens. BMC Microbiol. 9:109. doi: 10. 1186/1471-21809-109

Aulenta, F., Rossetti, S., Amalfitano, S., Majone, M., and Tandoi, V. (2013). Conductive magnetite nanoparticles accelerate the microbial reductive dechlorination of trichloroethene by promoting interspecies electron transfer processes. ChemSusChem 6, 433-436. doi: 10.1002/cssc.201200748

Biebl, H., and Pfennig, N. (1978). Growth yields of green sulfur bacteria in mixed cultures with sulfur and sulfate reducing bacteria. Arch. Microbiol. 117, 9-16. doi: 10.1007/Bf00689344

Bittner, M., Hilscherova, K., and Giesy, J. P. (2007). Changes of AhR-mediated activity of humic substances after irradiation. Environ. Int. 33, 812-816. doi: 10.1016/j.envint.2007.03.011

Boetius, A., Ravenschlag, K., Schubert, C. J., Rickert, D., Widdel, F., Gieseke, A., et al. (2000). A marine microbial consortium apparently mediating anaerobic oxidation of methane. Nature 407, 623-626. doi: 10.1038/35036572

Boone, D. R., Johnson, R. L., and Liu, Y. (1989). Diffusion of the interspecies electron carriers $\mathrm{H}-2$ and formate in methanogenic ecosystems and its implications in the measurement of $\mathrm{Km}$ for $\mathrm{H}-2$ or formate uptake. Appl. Environ. Microbiol. 55, 1735-1741.

Braunschweig, J., Bosch, J., and Meckenstock, R. U. (2013). Iron oxide nanoparticles in geomicrobiology: from biogeochemistry to bioremediation. N. Biotechnol. 30, 793-802. doi: 10.1016/j.nbt.2013.03.008

Brutinel, E. D., and Gralnick, J. A. (2012). Shuttling happens: soluble flavin mediators of extracellular electron transfer in Shewanella. Appl. Microbiol. Biotechnol. 93, 41-48. doi: 10.1007/s00253-011-3653-0

Bryant, M. P., Wolin, E. A., Wolin, M. J., and Wolfe, R. S. (1967). Methanobacillus omelianskii, a symbiotic association of two species of bacteria. Arch. Mikrobiol. 59, 20-31. doi: 10.1007/BF00406313

Butler, J. E., Kaufmann, F., Coppi, M. V., Nunez, C., and Lovley, D. R. (2004). MacA, a diheme c-type cytochrome involved in $\mathrm{Fe}(\mathrm{III})$ reduction by Geobacter sulfurreducens. J. Bacteriol. 186, 4042-4045. doi: 10.1128/JB.186.12.4042-4045.2004

Chen, S., Rotaru, A.-E., Shrestha, P. M., Malvankar, N., Liu, F., Fan, W., et al. (2014). Promoting interspecies electron transfer with biochar. Sci. Rep. (in press).

Conrad, R. (2009). The global methane cycle: recent advances in understanding the microbial processes involved. Environ. Microbiol. Rep. 1, 285-292. doi: 10.1111/j.1758-2229.2009.00038.x

de Bok, F. A., Plugge, C. M., and Stams, A. J. (2004). Interspecies electron transfer in methanogenic propionate degrading consortia. Water Res. 38, 1368-1375. doi: 10.1016/j.watres.2003.11.028

Ding, Y. H. R., Hixson, K. K., Aklujkar, M. A., Lipton, M. S., Smith, R. D., Lovley, D. R., et al. (2008). Proteome of Geobacter sulfurreducens grown with $\mathrm{Fe}$ (III) oxide or $\mathrm{Fe}(\mathrm{III})$ citrate as the electron acceptor. Biochim. Biophys. Acta 1784, 1935-1941. doi: 10.1016/j.bbapap.2008.06.011

Dong, X., and Stams, A. J. (1995). Evidence for H2 and formate formation during syntrophic butyrate and propionate degradation. Anaerobe 1, 35-39. doi: 10.1016/S1075-9964(95)80405-6

Feng, Y., Lin, X., Yu, Y., Zhang, H., Chu, H., and Zhu, J. (2013). Elevated ground-level $\mathrm{O}_{3}$ negatively influences paddy methanogenic archaeal community. Sci. Rep. 3, 3193. doi: $10.1038 /$ srep03193

Grosskopf, R., Janssen, P. H., and Liesack, W. (1998). Diversity and structure of the methanogenic community in anoxic rice paddy soil microcosms as examined by cultivation and direct $16 \mathrm{~S}$ rRNA gene sequence retrieval. Appl. Environ. Microbiol. 64, 960-969.

Hattori, S., Luo, H., Shoun, H., and Kamagata, Y. (2001). Involvement of formate as an interspecies electron carrier in a syntrophic acetate-oxidizing anaerobic microorganism in coculture with methanogens. J. Biosci. Bioeng. 91, 294-298.

Holmes, D. E., Chaudhuri, S. K., Nevin, K. P., Mehta, T., Methe, B. A., Liu, A., et al. (2006). Microarray and genetic analysis of electron transfer to electrodes in Geobacter sulfurreducens. Environ. Microbiol. 8, 1805-1815. doi: 10.1111/j.14622920.2006.01065.x

Inoue, K., Qian, X., Morgado, L., Kim, B. C., Mester, T., Izallalen, M., et al. (2010). Purification and characterization of OmcZ, an outer-surface, octaheme c-type cytochrome essential for optimal current production by Geobacter sulfurreducens. Appl. Environ. Microbiol. 76, 3999-4007. doi: 10.1128/AEM.00027-10 
Jiang, S., Park, S., Yoon, Y., Lee, J. H., Wu, W. M., Phuoc Dan, N., et al. (2013). Methanogenesis facilitated by geobiochemical iron cycle in a novel syntrophic methanogenic microbial community. Environ. Sci. Technol. 47, 10078-10084. doi: 10.1021/es402412c

Jones, E. J. P., Voytek, M. A., Corum, M. D., and Orem, W. H. (2010). Stimulation of methane generation from nonproductive coal by addition of nutrients or a microbial consortium. Appl. Environ. Microbiol. 76, 7013-7022. doi 10.1128/Aem.00728-10

Kaden, J., Galushko, A. S., and Schink, B. (2002). Cysteine-mediated electron transfer in syntrophic acetate oxidation by cocultures of Geobacter sulfurreducens and Wolinella succinogenes. Arch. Microbiol. 178, 53-58. doi: 10.1007/s00203-0020425-3

Kato, S., Hashimoto, K., and Watanabe, K. (2012a). Methanogenesis facilitated by electric syntrophy via (semi)conductive iron-oxide minerals. Environ. Microbiol. 14, 1646-1654. doi: 10.1111/j.1462-2920.2011.02611.x

Kato, S., Hashimoto, K., and Watanabe, K. (2012b). Microbial interspecies electron transfer via electric currents through conductive minerals. Proc. Natl. Acad. Sci. U.S.A. 109, 10042-10046. doi: 10.1073/pnas.1117592109

Kleerebezem, R., Hulshoff Pol, L. W., and Lettinga, G. (1999). Anaerobic degradation of phthalate isomers by methanogenic consortia. Appl. Environ. Microbiol. 65, 1152-1160.

Leang, C., Qian, X. L., Mester, T., and Lovley, D. R. (2010). Alignment of the c-type cytochrome OmcS along pili of Geobacter sulfurreducens. Appl. Environ. Microbiol. 76, 4080-4084. doi: 10.1128/Aem.00023-10

Liu, F. H., Rotaru, A.-E., Shrestha, P. M., Malvankar, N. S., Nevin, K. P., and Lovley, D. R. (2012). Promoting direct interspecies electron transfer with activated carbon. Energy Environ. Sci. 5, 8982-8989. doi: 10.1039/C2ee22459c

Liu, F., Rotaru, A.-E., Shrestha, P. M., Malvankar, N. S., Nevin, K., and Lovley, D. (2014). Magnetite compensates for the lack of a pilin-associated c-type cytochrome in extracellular electron exchange. Environ. Microbiol. doi: 10.1111/1462-2920.12485 [Epub ahead of print].

Liu, X., Tremblay, P. L., Malvankar, N. S., Nevin, K. P., Lovley, D. R., and Vargas, M. (2013). Geobacter sulfurreducens strain expressing Pseudomonas aeruginosa type IV pili localizes OmcS on pili but is deficient in $\mathrm{Fe}$ (III) oxide reduction and current production. Appl. Environ. Microbiol. 80, 1219-1224 doi: 10.1128/AEM.0293813

Lloyd, J. R., Leang, C., Hodges Myerson, A. L., Coppi, M. V., Cuifo, S., Methe, B., et al. (2003). Biochemical and genetic characterization of PpcA, a periplasmic c-type cytochrome in Geobacter sulfurreducens. Biochem. J. 369, 153-161. doi: 10.1042/BJ20020597

Lovley, D. R. (2011). Live wires: direct extracellular electron exchange for bioenergy and the bioremediation of energy-related contamination. Energy Environ. Sci. 4, 4896-4906. doi: 10.1039/C1ee02229f

Lovley, D. R. (2012). Long-range electron transport to $\mathrm{Fe}(\mathrm{III})$ oxide via pili with metallic-like conductivity. Biochem. Soc. Trans. 40, 1186-1190. doi: 10.1042/BST20120131

Lovley, D. R., Coates, J. D., Bluntharris, E. L., Phillips, E. J. P., and Woodward, J. C. (1996). Humic substances as electron acceptors for microbial respiration. Nature 382, 445-448. doi: 10.1038/382445a0

Lovley, D. R., and Ferry, J. G. (1985). Production and consumption of H2 during growth of Methanosarcina spp. on acetate. Appl. Environ. Microbiol. 49, 247-249.

Lovley, D. R., Fraga, J. L., Blunt-Harris, E. L., Hayes, L. A., Phillips, E. J. P., and Coates, J. D. (1998). Humic substances as a mediator for microbially catalyzed metal reduction. Acta Hydrochim. Hydrobiol. 26, 152-157. doi: 10.1002/(Sici)1521401x(199805) 26:3<152::Aid-Aheh152>3.0.Co;2-D

Lovley, D. R., Fraga, J. L., Coates, J. D., and Blunt-Harris, E. L. (1999). Humics as an electron donor for anaerobic respiration. Environ. Microbiol. 1, 89-98. doi: 10.1046/j.1462-2920.1999.00009.x

Lovley, D. R., Ueki, T., Zhang, T., Malvankar, N. S., Shrestha, P. M., Flanagan, K. A., et al. (2011). Geobacter: the microbe electric's physiology, ecology, and practical applications. Adv. Microb. Physiol. 59, 1-100. doi: 10.1016/B978-0-12-3876614.00004-5

Malvankar, N. S., and Lovley, D. R. (2012). Microbial nanowires: a new paradigm for biological electron transfer and bioelectronics. ChemSusChem 5, 1039-1046. doi: $10.1002 /$ cssc. 201100733

Malvankar, N. S., and Lovley, D. R. (2014). Microbial nanowires for bioenergy applications. Curr. Opin. Biotechnol. 27, 88-95. doi: 10.1016/j.copbio.2013.12.003

Malvankar, N. S., Vargas, M., Nevin, K. P., Franks, A. E., Leang, C., Kim, B. C., et al. (2011). Tunable metallic-like conductivity in microbial nanowire networks. Nat. Nanotechnol. 6, 573-579. doi: 10.1038/Nnano.2011.119
Marsili, E., Baron, D. B., Shikhare, I. D., Coursolle, D., Gralnick, J. A., and Bond, D. R. (2008). Shewanella secretes flavins that mediate extracellular electron transfer. Proc. Natl. Acad. Sci. U.S.A. 105, 3968-3973. doi: 10.1073/pnas.0710525105

McInerney, M. J., Sieber, J. R., and Gunsalus, R. P. (2011). Microbial syntrophy: ecosystem-level biochemical cooperation. Microbe 6, 479-485.

Mehta, T., Coppi, M. V., Childers, S. E., and Lovley, D. R. (2005). Outer membrane c-type cytochromes required for $\mathrm{Fe}(\mathrm{III})$ and $\mathrm{Mn}(\mathrm{IV})$ oxide reduction in Geobacter sulfurreducens. Appl. Environ. Microbiol. 71, 8634-8641. doi: 10.1128/AEM.71.12.8634-8641.2005

Milucka, J., Ferdelman, T. G., Polerecky, L., Franzke, D., Wegener, G., Schmid, M., et al. (2012). Zero-valent sulphur is a key intermediate in marine methane oxidation. Nature 491, 541-546. doi: 10.1038/Nature11656

Moran, J. J., Beal, E. J., Vrentas, J. M., Orphan, V. J., Freeman, K. H., and House, C. H. (2008). Methyl sulfides as intermediates in the anaerobic oxidation of methane. Environ. Microbiol. 10, 162-173. doi: 10.1111/j.1462-2920.2007.01441.x

Moreira, C. G., Palmer, K., Whiteley, M., Sircili, M. P., Trabulsi, L. R., Castro, A. F. P., et al. (2006). Bundle-forming pili and EspA are involved in biofilm formation by enteropathogenic Escherichia coli. J. Bacteriol. 188, 3952-3961. doi: 10.1128/Jb.00177-06

Morita, M., Malvankar, N. S., Franks, A. E., Summers, Z. M., Giloteaux, L., Rotaru, A.-E., et al. (2011). Potential for direct interspecies electron transfer in methanogenic wastewater digester aggregates. MBio 2, e00159-e00111. doi: 10.1128/mBio.00159-11

Morris, B. E., Henneberger, R., Huber, H., and Moissl-Eichinger, C. (2013). Microbial syntrophy: interaction for the common good. FEMS Microbiol. Rev. 37, 384-406. doi: 10.1111/1574-6976.12019

Nagarajan, H., Embree, M., Rotaru, A.-E., Shrestha, P. M., Feist, A. M., Palsson, B. O., et al. (2013). Characterization and modelling of interspecies electron transfer mechanisms and microbial community dynamics of a syntrophic association. Nat. Commun. 4, 2809. doi: 10.1038/ncomms3809

Nedwell, D. B., and Banat, I. M. (1981). Hydrogen as an electron-donor for sulfatereducing bacteria in slurries of salt-marsh sediment. Microb. Ecol. 7, 305-313. doi: 10.1007/Bf02341425

Nevin, K. P., Kim, B. C., Glaven, R. H., Johnson, J. P., Woodard, T. L., Methe, B. A., et al. (2009). Anode biofilm transcriptomics reveals outer surface components essential for high density current production in Geobacter sulfurreducens fuel cells. PLoS ONE 4:e5628. doi: 10.1371/journal.pone.0005628

Newman, D. K., and Kolter, R. (2000). A role for excreted quinones in extracellular electron transfer. Nature 405, 94-97. doi: 10.1038/35011098

Oxaran, V., Ledue-Clier, F., Dieye, Y., Herry, J. M., Pechoux, C., Meylheuc, T., et al. (2012). Pilus biogenesis in Lactococcus lactis: molecular characterization and role in aggregation and biofilm formation. PLOS ONE 7:e50989. doi: 10.1371/journal.pone.0050989

Qian, X. L., Mester, T., Morgado, L., Arakawa, T., Sharma, M. L., Inoue, K., et al. (2011). Biochemical characterization of purified OmcS, a c-type cytochrome required for insoluble $\mathrm{Fe}(\mathrm{III})$ reduction in Geobacter sulfurreducens. Biochim. Biophys. Acta 1807, 404-412. doi: 10.1016/j.bbabio.2011.01.003

Qian, X. L., Reguera, G., Mester, T., and Lovley, D. R. (2007). Evidence that OmcB and OmpB of Geobacter sulfurreducens are outer membrane surface proteins. FEMS Microbiol. Lett. 277, 21-27. doi: 10.1111/j.1574-6968.2007.00915.x

Reguera, G., Mccarthy, K. D., Mehta, T., Nicoll, J. S., Tuominen, M. T., and Lovley, D. R. (2005). Extracellular electron transfer via microbial nanowires. Nature 435, 1098-1101. doi: 10.1038/Nature03661

Reguera, G., Nevin, K. P., Nicoll, J. S., Covalla, S. F., Woodard, T. L., and Lovley, D. R. (2006). Biofilm and nanowire production leads to increased current in Geobacter sulfurreducens fuel cells. Appl. Environ. Microbiol. 72, 7345-7348. doi: 10.1128/AEM.01444-06

Reguera, G., Pollina, R. B., Nicoll, J. S., and Lovley, D. R. (2007). Possible nonconductive role of Geobacter sulfurreducens pilus nanowires in biofilm formation. J. Bacteriol. 189, 2125-2127. doi: 10.1128/Jb.01284-06

Richter, H., Nevin, K. P., Jia, H., Lowy, D. A., Lovley, D. R., and Tender, L. M. (2009). Cyclic voltammetry of biofilms of wild type and mutant Geobacter sulfurreducens on fuel cell anodes indicates possible roles of $\mathrm{OmcB}, \mathrm{OmcZ}$, type IV pili, and protons in extracellular electron transfer. Energy Environ. Sci. 2, 506-516. doi: $10.1039 / \mathrm{b} 816647 \mathrm{a}$

Rotaru, A.-E., Shrestha, P. M., Liu, F., Shrestha, M., Shrestha, D., Embree, M., et al. (2014). A new model for electron flow during anaerobic digestion: direct interspecies electron transfer to Methanosaeta for the reduction of carbon dioxide to methane. Energy Environ. Sci. 7, 408-415. doi: 10.1039/c3ee42189a 
Rotaru, A.-E., Shrestha, P. M., Liu, F., Ueki, T., Nevin, K., Summers, Z. M., etal. (2012). Interspecies electron transfer via hydrogen and formate rather than direct electrical connections in cocultures of Pelobacter carbinolicus and Geobacter sulfurreducens. Appl. Environ. Microbiol. 78, 7645-7651. doi: 10.1128/AEM.01946-12

Schink, B., and Stams, A. J. M. (2006). Syntrophism among Prokaryotes. Prokaryotes: A Handbook on the Biology of Bacteria, 3rd Edn, Vol. 2, (New York: Springer Verlag), 309-335.

Schink, B., and Stams, A. M. (2013). "Syntrophism Among Prokaryotes," in The Prokaryotes, eds E. Rosenberg, E. Delong, S. Lory, E. Stackebrandt, and F. Thompson (New York: Springer Berlin Heidelberg), 471-493.

Schut, G. J., and Adams, M. W. W. (2009). The iron-hydrogenase of thermotoga maritima utilizes ferredoxin and NADH synergistically: a new perspective on anaerobic hydrogen production. J. Bacteriol. 191, 4451-4457. doi: 10.1128/Jb.01582-08

Shrestha, P. M., Rotaru, A.-E., Aklujkar, M., Liu, F., Shrestha, M., Summers, Z. M., et al. (2013a). Syntrophic growth with direct interspecies electron transfer as the primary mechanism for energy exchange. Environ. Microbiol. Rep. 5, 904-910. doi: 10.1111/1758-2229.12093

Shrestha, P. M., Rotaru, A.-E., Summers, Z. M., Shrestha, M., Liu, F., and Lovley, D. R. (2013b). Transcriptomic and genetic analysis of direct interspecies electron transfer. Appl. Environ. Microbiol. 79, 2397-2404. doi: 10.1128/AEM.03837-12

Sieber, J. R., Le, H. M., and Mcinerney, M. J. (2014). The importance of hydrogen and formate transfer for syntrophic fatty, aromatic and alicyclic metabolism. Environ. Microbiol. 16, 177-188. doi: 10.1111/1462-2920.12269

Sieber, J. R., Mcinerney, M. J., and Gunsalus, R. P. (2012). Genomic insights into syntrophy: the paradigm for anaerobic metabolic cooperation. Annu. Rev. Microbiol. 66, 429-452. doi: 10.1146/annurev-micro-090110-102844

Sieber, J. R., Sims, D. R., Han, C., Kim, E., Lykidis, A., Lapidus, A. L., et al. (2010). The genome of Syntrophomonas wolfei: new insights into syntrophic metabolism and biohydrogen production. Environ. Microbiol. 12, 2289-2301. doi: 10.1111/j.14622920.2010.02237.x

Snider, R. M., Strycharz-Glaven, S. M., Tsoi, S. D., Erickson, J. S., and Tender, L. M. (2012). Long-range electron transport in Geobacter sulfurreducens biofilms is redox gradient-driven. Proc. Natl. Acad. Sci. U.S.A. 109, 15467-15472. doi: 10.1073/pnas.1209829109

Sousa, D. Z., Smidt, H., Alves, M. M., and Stams, A. J. M. (2007). Syntrophomona zehnderi sp nov., an anaerobe that degrades long-chain fatty acids in co-culture with Methanobacterium formicicum. Int. J. Syst. Evol. Microbiol. 57, 609-615. doi: 10.1099/ijs.0.647340

Stams, A. J., De Bok, F. A., Plugge, C. M., Van Eekert, M. H., Dolfing, J., and Schraa, G. (2006). Exocellular electron transfer in anaerobic microbial communities. Environ. Microbiol. 8, 371-382. doi: 10.1111/j.1462-2920.2006.00989.x

Stams, A. J., and Plugge, C. M. (2009). Electron transfer in syntrophic communities of anaerobic bacteria and archaea. Nat. Rev. Microbiol. 7, 568-577. doi: 10.1038/nrmicro2166

Strycharz-Glaven, S. M., Snider, R. M., Guiseppi-Elie, A., and Tender, L. M. (2011). On the electrical conductivity of microbial nanowires and biofilms. Energy Environ. Sci. 4, 4366-4379. doi: 10.1039/clee01753e

Strycharz, S. M., Glaven, R. H., Coppi, M. V., Gannon, S. M., Perpetua, L. A., Liu, A., et al. (2011). Gene expression and deletion analysis of mechanisms for electron transfer from electrodes to Geobacter sulfurreducens. Bioelectrochemistry 80, 142-150. doi: 10.1016/j.bioelechem.2010.07.005

Summers, Z. M., Fogarty, H. E., Leang, C., Franks, A. E., Malvankar, N. S., and Lovley, D. R. (2010). Direct exchange of electrons within aggregates of an evolved syntrophic coculture of anaerobic bacteria. Science 330, 1413-1415. doi: $10.1126 /$ science. 1196526
Thiele, J. H., and Zeikus, J. G. (1988). Control of interspecies electron flow during anaerobic digestion: significance of formate transfer versus hydrogen transfer during syntrophic methanogenesis in flocs. Appl. Environ. Microbiol. 54, $20-29$.

Tremblay, P. L., Aklujkar, M., Leang, C., Nevin, K. P., and Lovley, D. (2012). A genetic system for Geobacter metallireducens: role of the flagellin and pilin in the reduction of Fe(III) oxide. Environ. Microbiol. Rep. 4, 82-88. doi: 10.1111/j.17582229.2011.00305.x

Ueki, T., and Lovley, D. R. (2010). Genome-wide gene regulation of biosynthesis and energy generation by a novel transcriptional repressor in Geobacter species. Nucleic Acids Res. 38, 810-821. doi: 10.1093/nar/ gkp1085

Vargas, M., Malvankar, N. S., Tremblay, P. L., Leang, C., Smith, J. A., Patel, P., et al. (2013). Aromatic amino acids required for pili conductivity and long-range extracellular electron transport in Geobacter sulfurreducens. MBio 4, e00105e00113. doi: 10. 1128/mBio.00105-13

Vavilin, V. A., Qu, X., Mazeas, L., Lemunier, M., Duquennoi, C., He, P. J., et al. (2008). Methanosarcina as the dominant aceticlastic methanogens during mesophilic anaerobic digestion of putrescible waste. Antonie Van Leeuwenhoek 94, 593-605. doi: 10.1007/s10482-008-9279-2

von Canstein, H., Ogawa, J., Shimizu, S., and Lloyd, J. R. (2008). Secretion of flavins by Shewanella species and their role in extracellular electron transfer. Appl. Environ. Microbiol. 74, 615-623. doi: 10.1128/Aem. 01387-07

Wintermute, E. H., and Silver, P. A. (2010). Dynamics in the mixed microbial concourse. Genes Dev. 24, 2603-2614. doi: 10.1101/gad.1985210

Ying, Y., Yu, K., Xia, Y., Lau, F. T., Tang, D. T., Fung, W. C., et al. (2014). Metagenomic analysis of sludge from full-scale anaerobic digesters operated in municipal wastewater treatment plants. Appl. Microbiol. Biotechnol. doi: 10.1007/s00253-014-5648-0 [Epub ahead of print].

Zhou, M., Chen, J., Freguia, S., Rabaey, K., and Keller, J. (2013a). Carbon and electron fluxes during the electricity driven 1,3-propanediol biosynthesis from glycerol. Environ. Sci. Technol. 47, 11199-11205. doi: 10.1021/es402132r

Zhou, S., Xu, J., Yang, G., and Zhuang, L. (2013b). Methanogenesis affected by the co-occurrence of iron(III) oxides and humic substances. FEMS Microbiol. Ecol. 88, 107-120. doi: 10.1111/1574-6941.12274

Zindel, U., Freudenberg, W., Rieth, M., Andreesen, J. R., Schnell, J., and Widdel, F. (1988). Eubacterium-acidaminophilum Sp-nov, a versatile amino acid-degrading anaerobe producing or utilizing H-2 or formate - description and enzymatic studies. Arch. Microbiol. 150, 254-266. doi: 10.1007/Bf00407789

Conflict of Interest Statement: The authors declare that the research was conducted in the absence of any commercial or financial relationships that could be construed as a potential conflict of interest.

Received: 28 March 2014; accepted: 30 April 2014; published online: 16 May 2014. Citation: Shrestha PM and Rotaru A-E (2014) Plugging in or going wireless: strategies for interspecies electron transfer. Front. Microbiol. 5:237. doi: 10.3389/fmicb.2014. 00237

This article was submitted to Terrestrial Microbiology, a section of the journal Frontiers in Microbiology.

Copyright (c) 2014 Shrestha and Rotaru. This is an open-access article distributed under the terms of the Creative Commons Attribution License (CC BY). The use, distribution or reproduction in other forums is permitted, provided the original author(s) or licensor are credited and that the original publication in this journal is cited, in accordance with accepted academic practice. No use, distribution or reproduction is permitted which does not comply with these terms. 